\title{
molecules
}

ISSN 1420-3049

(C) 2007 by MDPI

www.mdpi.org/molecules

Full Paper

\section{Essential Oils of Satureja Species: Insecticidal Effect on Culex pipiens Larvae (Diptera: Culicidae)}

\author{
Antonios Michaelakis ${ }^{1}$, Spiridon A. Theotokatos ${ }^{2}$, Georgios Koliopoulos ${ }^{1}$ and \\ Nikos G. Chorianopoulos ${ }^{3, *}$ \\ ${ }^{1}$ Benaki Phytopathological Institute, 8 S. Delta Str. 14561 Kifissia, Athens, Greece \\ ${ }^{2}$ Agroindustrial Robola Growers Cooperative of Kefalllinia, Omala, 28100 Kefallinia, Greece \\ ${ }^{3}$ Chemistry Laboratory, Agricultural University of Athens, Iera odos 75, Athens, 11855, Greece \\ * Author to whom correspondence should be addressed; E-mail: nchorian@aua.gr
}

Received: 9 November 2007; in revised form: 7 December 2007 / Accepted: 7 December 2007 / Published: 10 December 2007

\begin{abstract}
The chemical composition of the essential oils of the wild growing plants of Greek S. spinosa L., S. parnassica subsp. parnassica Heldr.\& Sart ex Boiss., S. thymbra and S. montana were determined by GC and GC/MS analysis. The larvicidal activities of the essential oils were assayed against Culex pipiens biotype molestus. The analytical data indicated that various monoterpene hydrocarbons and phenolic monoterpenes constitute the major constituents of the oils, but their concentration varied greatly among the oils examined. The bioassay results indicated that the oils possess significant larvicidal activities and represent an inexpensive source of natural substances mixture that exhibit potentials for use to control the mosquito larvae.
\end{abstract}

Keywords: Essential oils, Satureja sp., mosquito control, larvicidal activity, Culex pipiens biotype molestus

\section{Introduction}

Mosquitoes are considered as vectors for some of the most devastating diseases of human history (malaria, West Nile virus (WN), dengue, filariasis, yellow fever and other vector-borne diseases). 
Recent reports have emerged the resurgence of several mosquito-borne diseases in Western world as a consequence of the increasing resistance of mosquitoes to commercial insecticides [1]. In this regard, the recrudescence of WN virus -a pronounced flavivirus mediated disease- which is transmitted in natural cycles between birds and mosquitoes but also infects humans, represent a characteristic example that occurred in Middle East, Africa, India, United States and Europe [1, 2]. Members of $C x$. pipiens complex are responsible for the transmission of this vector-borne disease [3]. The dramatic emergence of a WN epidemic in the New York City area on 1999 is a reminder that a virus introduction into a new ecosystem (or a different hemisphere), might have an unexpected impact on public health. As a result, WN has spread to all US states, Canada, Mexico, Central America and the Caribbean $[4,5]$. It should be noted that minor local climate changes usually force these populations to move into new areas introducing the pathogens that they transmit [1, 3, 6, 7].

Additional factors of the recrudescence of the aforementioned diseases that may also be considered include the large numbers of tourists and immigrants that may carry parasites and pathogens, the growing number of breeding sites in contemporary societies and mainly insect resistance to conventional insecticides. Since 1947, year that the first incidence of DDT resistance was encountered, more than 100 mosquito species have been reported as resistant to one or more insecticides [8, 9]. It must also be pointed out that the development of yellow fever vaccine has sufficiently diminished its spread but there are no similar vaccines available for malaria, dengue, WN and other arbovirus mediated diseases. Thus, the only means to control their incidence is to decrease the population of mosquitoes that transmit them. In this context, the use of various organophosphorous and pyrethroid insecticides constitutes a common practice for public authorities. Experimental data have indicated that such use of aerial toxicants to control the population of adult mosquitoes is not effective, since they are highly domesticated and spraying does not affect many mosquitoes that rest indoors in hidden places. On the contrary, the systematic application of larvicides onto their breeding places constitutes a very effective method to reduce their densities to dengue level, eliminating the possibility of development of mosquito transmitted epidemics like WN and yellow fever [10]. For this purpose, Temephos and compounds obtained from Bacillus thuringiensis ssp. israelensis and Bacillus sphaericus are commonly used as larvicides.

The recent negative consumer perceptions concerning the use of chemicals as larvicides has shifted the research effort towards the development of alternatives that the public perceives as natural, such as essential oils and plant extracts. This application of essential oils may be rationalized considering that co-evolution has equipped plants with a plethora of chemical defenses against insect predators [11] and this has initiated a considerable research activity concerning the use of plant parts and/or extracts to control insects. On 1991 Sukumar et al. [12] reviewed the use of natural products derived from 344 different plant species to control mosquito populations. Thus, the plant derived products have received increased attention from scientists and nowadays more than 2,000 plant species have already been screened as potent insecticides providing possible lead candidates to replace synthetic chemical insecticides for controlling mosquito larvae [13-23]. In this regard, plant extracts of the Lamiaceae family present an intriguing case, since they comprise a significant source of potential mosquito control agents [12, 21]. Plants belonging to the Lamiaceae family, order Lamiales, subclass Asteridae, Dicotyledonae, include 251 genera and almost 6700 species with cosmopolitan distribution. In Europe 41 genera of the family occur that are composed by 450 species. Satureja L. is one of the 38 genera 
found in Greece and is represented by six species [24]. Their essential oils are already known to exert significant antimicrobial [25-27] and insecticidal [21, 28, 29] activities.

Table 1. Collection Data.

\begin{tabular}{|c|c|c|c|c|c|}
\hline Species & Abbreviation & Vegetative stage & Date & Location & $\begin{array}{c}\text { Altitude } \\
(\mathrm{m})\end{array}$ \\
\hline Satureja montana & SM & Full flowering & $20 \mathrm{Jul} 04$ & $\begin{array}{c}\text { Mt Koziakas, continental } \\
\text { Greece }\end{array}$ & 800 \\
\hline Satureja thymbra & STDI & Full flowering & 14 Jul 04 & Mt Dikti, Crete & 1450 \\
\hline Satureja thymbra & ST & Just before flowering & 05 Jun 04 & $\begin{array}{c}\text { Mt Immitos, continental } \\
\text { Greece }\end{array}$ & 350 \\
\hline Satureja spinosa & SSP & Just before flowering & $14 \mathrm{Jul} 04$ & Mt Dikti, Crete & 1650 \\
\hline $\begin{array}{c}\text { Satureja parnassica } \\
\text { ssp. parnassica }\end{array}$ & SP & Just before flowering & $10 \mathrm{Jul} 04$ & Mt Parnon, Peloponnesus & 1800 \\
\hline
\end{tabular}

The main goal of our investigation was to evaluate the insecticidal activities - under controlled laboratory conditions - of Satureja spp. essential oils obtained from plants growing wild in Greece. For this purpose we have determine their efficacy as potential alternative natural means for mosquito control against immature mosquito species using $C x$. pipiens larvae. The latter, except for their medical importance (aside from the WN virus, Culex are also the major vectors of filariasis and Japanese encephalitis), share many biological characteristics with other mosquito vectors.

Table 2. Essential Oils Yields.

\begin{tabular}{cccc}
\hline Species (Abbrev.) & Part distilled & $\begin{array}{c}\text { Weight of } \\
\text { aerial parts (g) }\end{array}$ & $\begin{array}{c}\text { Volume of oil } \\
(\mathrm{mL})\end{array}$ \\
\hline Satureja montana (SM) & Stems, leaves \& flowers (fresh) & 230 & 3.5 \\
Satureja thymbra (STDI) & Stems, leaves \& flowers (fresh) & 250 & 4 \\
Satureja thymbra (ST) & Stems \& leaves (fresh) & 200 & 4.4 \\
Satureja spinosa (SSP) & Stems \& leaves (fresh) & 200 & 0.5 \\
Satureja parnassica ssp. & Stems \& leaves (fresh) & 200 & 2.2 \\
\hline parnassica (SP) & & & \\
\hline
\end{tabular}

\section{Results and Discussion}

\section{Phytochemical analysis}

More than fifty phytochemicals representing 96.52 to $98.12 \%$ of the respective samples have been identified as constituents of the essential oils by combined GC and GC/MS analyses. The detailed qualitative and quantitative analytical data of the main components (and their respective retention 
indices) of steam volatiles have been summarized in Table 3. The phytochemical content among the respective essential oils of Satureja species varied greatly. Similarly, $S$. thymbra specimens obtained from different locations showed large of prevalent their phenolic content. In most cases however, carvacrol and/or thymol constituted the major component of the oils tested (Table 3), while the sum of these two isomeric phenolic monoterpenes (carvacrol and thymol) and their biosynthetic precursors $p$ cymene and $\gamma$-terpinene [30] represented the bulk (ca 74\%) of the essential oils. In the case of Satureja thymbra (ST), the essential oils obtained were exceptionally poor in phenolic monoterpenes (44.42\%), while their content of monoterpene hydrocarbons $p$-cymene and $\gamma$-terpinene was quite high (30.51\%). These results are in accordance with previous observations concerning several other Greek wild populations of the same family [31]. The presence of other monoterpene hydrocarbons, such as myrcene, $\alpha$-terpinene, was also assayed in small quantities, while monoterpene alcohols such as linalool, borneol and terpin-4-ol were detected in all of Satureja specimen oils. Finally, it is interesting to point out that $\beta$-caryophyllene was detected as major component of the oils tested, while the essential oils of SSP, ST and STDI were also found to contain large amounts of thymol, methyl ether (4.05, 4.12 and $4.34 \%$ respectively).

Table 3. Chemical Constituents of the Essential Oils tested.

\begin{tabular}{|c|c|c|c|c|c|c|c|}
\hline \multirow[b]{2}{*}{ Compound } & \multicolumn{5}{|c|}{ GC area \% } & \multirow[b]{2}{*}{$\mathrm{KI}^{\mathrm{c}}$} & \multirow[b]{2}{*}{ 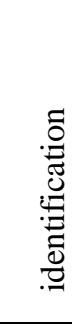 } \\
\hline & 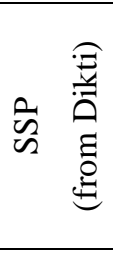 & 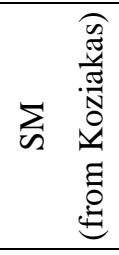 & 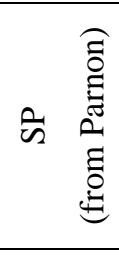 & 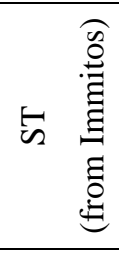 & 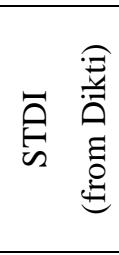 & & \\
\hline$\alpha$-thujene & 0.43 & 0.56 & 0.72 & 1.14 & 0.49 & 923 & $\mathrm{a}$ \\
\hline$\alpha$-pinene & 0.15 & 0.35 & 0.54 & 2.32 & 0.38 & 932 & $a, b$ \\
\hline camphene & 0.09 & 0.32 & 0.29 & 1.17 & - & 947 & $\mathrm{a}$ \\
\hline sabinene & - & $\operatorname{tr}$ & 0.14 & 0.05 & $\operatorname{tr}$ & 974 & $\mathrm{a}$ \\
\hline$\beta$-pinene & 0.12 & 0.14 & 0.05 & 1.32 & - & 976 & $a, b$ \\
\hline 1-octen-3-ol & 0.42 & - & 0.36 & - & 0.31 & 979 & $\mathrm{a}$ \\
\hline myrcene & 0.88 & 1.9 & 1.05 & 1.56 & 0.76 & 990 & $a, b$ \\
\hline 3-octanol & 0.17 & - & - & - & 0.22 & 991 & $\mathrm{a}$ \\
\hline$\alpha$-phellandrene & 0.11 & 0.17 & 0.32 & 0.28 & 0.14 & 1001 & $\mathrm{a}$ \\
\hline$\alpha$-terpinene & 0.94 & 1.97 & 0.98 & 1.79 & 0.48 & 1015 & $a, b$ \\
\hline p-cymene & 5.48 & 9.45 & 8.35 & 10.39 & 9.19 & 1024 & $a, b$ \\
\hline limonene & 0.84 & 0.16 & 0.92 & - & - & 1027 & $a, b$ \\
\hline 1,8-cineole & 0.14 & 0.05 & 0.48 & - & - & 1030 & $a, b$ \\
\hline Cis- $\beta$-ocimene & - & - & 1.44 & 0.34 & $\operatorname{tr}$ & 1039 & a \\
\hline benzene acetaldehyde & 0.29 & $\operatorname{tr}$ & - & - & - & 1041 & $\mathrm{a}$ \\
\hline trans- $\beta$-ocimene & 0.12 & $\operatorname{tr}$ & 1.36 & $\operatorname{tr}$ & - & 1048 & $\mathrm{a}$ \\
\hline$\gamma$-terpinene & 6.49 & 13.24 & 12.32 & 20.12 & 14.64 & 1058 & $a, b$ \\
\hline cis-sabinene hydrate & 0.32 & 0.08 & 0.22 & 0.37 & 0.88 & 1068 & $\mathrm{a}$ \\
\hline terpinolene & 0.16 & 0.18 & 0.07 & 0.09 & 0.22 & 1089 & $\mathrm{a}$ \\
\hline linalool & 0.94 & 1.22 & 0.82 & 0.38 & 0.82 & 1099 & $\mathrm{a}, \mathrm{b}$ \\
\hline nonanal & 0.14 & 0.17 & 0.36 & - & - & 1102 & $\mathrm{a}$ \\
\hline
\end{tabular}


Table 3. Cont.

\begin{tabular}{|c|c|c|c|c|c|c|c|}
\hline 1-terpineol & 0.05 & - & 0.05 & - & $\operatorname{tr}$ & 1131 & $\mathrm{a}$ \\
\hline borneol & 0.32 & 0.26 & 0.34 & 0.12 & 0.18 & 1166 & $a, b$ \\
\hline terpin-4-ol & 1.35 & 0.18 & 0.88 & 0.1 & 0.39 & 1177 & $a, b$ \\
\hline$p$-cymen-8-ol & 0.05 & $\operatorname{tr}$ & - & - & - & 1180 & $\mathrm{a}$ \\
\hline$\alpha$-terpineol & 0.24 & - & 0.27 & 0.05 & - & 1187 & $\mathrm{a}$ \\
\hline cis-dihydrocarvone & 0.19 & - & 0.12 & - & - & 1192 & $\mathrm{a}$ \\
\hline trans-dihydrocarvone & 0.12 & - & - & - & - & 1199 & $\mathrm{a}$ \\
\hline thymol, methyl ether & 4.05 & $\operatorname{tr}$ & 0.34 & 4.12 & 4.34 & 1235 & $\mathrm{a}$ \\
\hline thymol & 12.39 & 0.94 & 44.39 & 42.15 & 24.32 & 1286 & $a, b$ \\
\hline carvacrol & 47.12 & 55.42 & 6.36 & 2.27 & 30.39 & 1295 & $a, b$ \\
\hline thymol acetate & 0.28 & 0.29 & 0.25 & $\operatorname{tr}$ & 0.18 & 1357 & $\mathrm{a}$ \\
\hline eugenol & - & $\operatorname{tr}$ & - & 0.18 & 0.31 & 1358 & $\mathrm{a}$ \\
\hline$\alpha$-copaene & - & 0.05 & 0.14 & - & - & 1370 & $\mathrm{a}$ \\
\hline$\beta$-bourbonene & - & - & 0.25 & - & - & 1380 & $\mathrm{a}$ \\
\hline cis-carvacryl acetate & 1.87 & - & $\operatorname{tr}$ & - & - & 1381 & $\mathrm{a}$ \\
\hline$\beta$-caryophyllene & 4.98 & 3.68 & 4.42 & 5.47 & 4.89 & 1418 & $\mathrm{a}, \mathrm{b}$ \\
\hline$\beta$-gurjunene & - & - & 0.14 & - & - & 1426 & $\mathrm{a}$ \\
\hline aromadendrene & 0.39 & 0.19 & 0.28 & - & 0.21 & 1444 & a \\
\hline$\alpha$-humulene & 0.22 & 0.34 & 0.41 & 0.38 & 0.56 & 1450 & $\mathrm{a}$ \\
\hline trans- $\beta$-farnesene & $\operatorname{tr}$ & - & - & - & - & 1456 & $\mathrm{a}$ \\
\hline allo-aromadendrene & - & - & 0.23 & - & - & 1458 & $\mathrm{a}$ \\
\hline$\gamma$-muurolene & - & 0.07 & 0.05 & - & $\operatorname{tr}$ & 1475 & $\mathrm{a}$ \\
\hline germacrene D & - & 0.25 & 0.29 & 0.54 & - & 1483 & $\mathrm{a}$ \\
\hline bicyclogermacrene & 0.76 & 0.48 & 1.36 & 0.18 & 0.94 & 1494 & $\mathrm{a}$ \\
\hline$\alpha$-muurolene & - & - & $\operatorname{tr}$ & - & - & 1496 & $\mathrm{a}$ \\
\hline$\beta$-bisabolene & 3.26 & 1.97 & 2.82 & 0.36 & 0.76 & 1508 & a \\
\hline$\gamma$-cadinene & - & $\operatorname{tr}$ & $\operatorname{tr}$ & - & - & 1513 & $\mathrm{a}$ \\
\hline$\delta$-cadinene & - & 0.39 & 0.47 & $\operatorname{tr}$ & $\operatorname{tr}$ & 1524 & $\mathrm{a}$ \\
\hline spathulenol & 0.44 & 0.84 & 0.83 & 0.29 & 0.46 & 1571 & $\mathrm{a}, \mathrm{b}$ \\
\hline caryophyllene oxide & 1.16 & 1.07 & 1.29 & 0.34 & 1.37 & 1581 & $a, b$ \\
\hline viridiflorol & - & - & 0.14 & - & - & 1588 & $\mathrm{a}$ \\
\hline epi- $\alpha$-cadinol & - & - & 0.09 & - & - & 1633 & $\mathrm{a}$ \\
\hline$\alpha$-bisabolol & 0.24 & 0.14 & 0.11 & - & 0.29 & 1681 & $a, b$ \\
\hline phytol & 0.18 & - & - & - & - & 1939 & $\mathrm{a}$ \\
\hline total & 97.89 & 96.52 & 97.11 & 97.87 & 98.12 & & \\
\hline
\end{tabular}

${ }^{\mathrm{a}}$ Comparison of mass spectra with MS libraries and retention times

${ }^{\mathrm{b}}$ Comparison with authentic compounds

$\operatorname{tr}=$ concentration less than $0.05 \%$

${ }^{\mathrm{c}} \mathrm{KI}$, Kovats indices calculated against $\mathrm{C}_{8}$ to $\mathrm{C}_{24} n$-alkanes on the HP 5MS column. 


\section{Larvicidal Assays}

The larvicidal effects of the essential oils on fourth-instar larvae of $C x$. $p$. biotype molestus, are summarized in Table 4. To our knowledge, there is limited information on the activity of essential oils against this genus of mosquito and no reports on the essential oils of these Satureja spp. Previous investigations have indicated that various plant extracts displayed larvicidal effect on CX. pipiens [14, 20]. Furthermore, it has been reported that pure substances, such as thymol and carvacrol that are known ingredients of Lamiaceae essential oils, when screened for larvicidal activity against Cx. $p$. biotype molestus were found to be toxic to larvae [32]. Although, the concentrations of both ingredients that caused 50\% mortality ( $\mathrm{LC}_{50}$ ) were approximately equal (36 and 36.7 for thymol and carvacrol respectively), carvacrol was determined as more toxic on the basis of their LC $\mathrm{g}_{90}$ values and the linear model the slope.

Table 4. Larvicidal activity of the essential oils against Culex pipiens biotype molestus.

\begin{tabular}{cccc}
\hline Species (Abbrev.) & $\begin{array}{c}\mathrm{LC}_{50}(\mathrm{mg} / \mathrm{L}) \\
(95 \% \mathrm{CL})\end{array}$ & $\begin{array}{c}\mathrm{LC}_{95} \\
(\mathrm{mg} / \mathrm{L})\end{array}$ & Slope \\
\hline Satureja montana (SM) & 37.7 & 58.7 & 0.07 \\
Satureja thymbra (STDI) & $(30.5-44.1)$ & & 0.10 \\
Satureja thymbra (ST) & 64.4 & 59.8 & 0.14 \\
Satureja spinosa (SSP) & $(56.0-73.0)$ & 55.6 & 0.08 \\
Satureja parnassica ssp. & 44.5 & 76.4 & \\
Parnassica (SP) & $(40.6-52.6)$ & & 0.12 \\
\hline
\end{tabular}

The estimated $\mathrm{LC}_{50}$ values for SM and ST were 37.7 (range 30.5-44.1) and 44.5 (range 40.6-52.6) $\mathrm{mg} \mathrm{L}^{-1}$, and their $\mathrm{LC}_{95}$ value were 58.7 and $55.6 \mathrm{mg} \mathrm{L}^{-1}$ respectively, indicating that both essential oils were the more toxic among the oils tested and the ST oil was the most effective. The latter was based on the $\mathrm{LC}_{95}$ values and slope, although its mean $\mathrm{LC}_{50}$ value was somehow higher (but near the range of SM). These oils have been assayed to contain carvacrol or thymol as major components respectively (Table 3, \% GC area).

The essential oils obtained from the aerial parts of SSP and STDI were screened as toxic against larvae of $C x$. p. biotype molestus as indicated by their mean $\mathrm{LC}_{50}$ and $\mathrm{LC}_{95}$ values (56.1/76.4 and 64.4/ $79.8 \mathrm{mg} \mathrm{L}^{-1}$, respectively). There were the less active among the oils tested extracts even though they found to contain large amounts of phenolic constituents (Table 3). This may be rationalized considering that the larvicidal activity is a result of the synergistic effect of the phenolic compounds with other components that are present in the oils tested. Finally, the assayed LC50 and LC95 values for SP were 52.1 (range 50.8-53.8) and $65.6 \mathrm{mg} \mathrm{L}^{-1}$ respectively. 
The aforementioned results indicate that: a) the essential oils of wildly grown in Greece Satureja species were found to possess larvicidal activities against $C x . p$. biotype molestus; b) the oils of SM and ST were the most potent and their activity is superior when compared to previously reported results concerning other natural means [32]; c) the chemical composition of the essential oil varies depending on plant's vegetative stage. In this regard it must be pointed out that carvacrol constitute the major component during the flowering period, while thymol prevailed before and after flowering [33]. Since carvacrol constitute the most active component, the collection period affects greatly the larvicidal activity.

\section{Principal Component Analysis (PCA)}

The analytical and biological data, presented in Tables 3 and 4 respectively, were statistically verified through principal component analysis (Principal Component Analysis, PCA) indicating that the most effective oils were derived from plants of species Satureja thymbra (ST) and Satureja montana (SM).

In this regard, it must be noted that the monoterpene phenols -carvacrol and thymol- content constitute the variable that which influenced at the highest degree the variation of Axis 1 (PC 1, Figure 1). With respect to the principal component analysis (PCA) of the chemical composition, as the difference in carvacrol and thymol is increased, oils were assayed to display the most intense larvicidal activities (Table 4, Figure 1).

Figure 1. Principal component analysis (PCA) ordination of the essential oils chemical composition. Axis 1 (PC 1) accounts for the $85.4 \%$ of the total variance and Axis 2 (PC 2) accounts for a further $12.4 \%$ of the total variance. Arrows indicate the ordination scores of the main variables carvacrol and thymol.

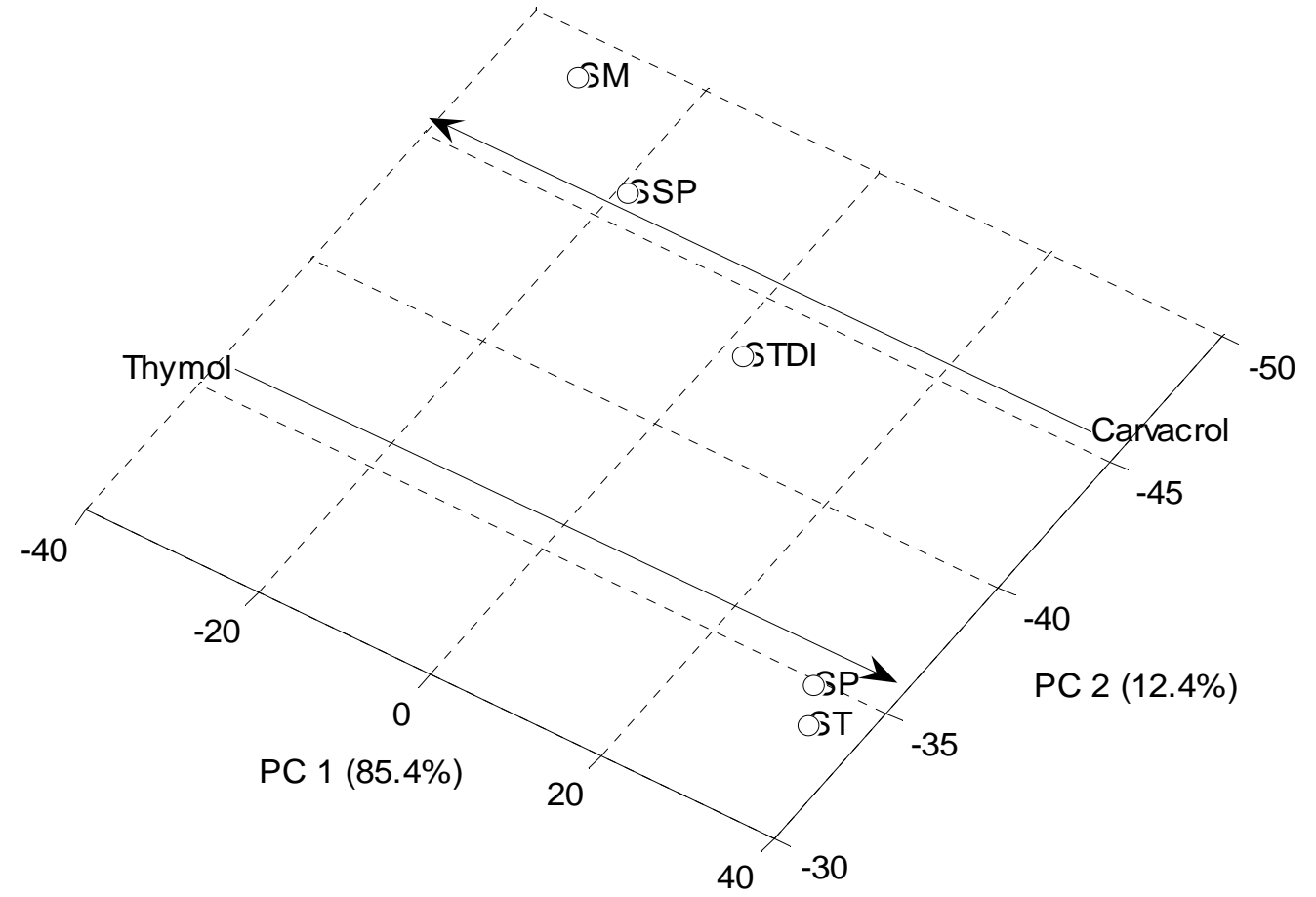




\section{Conclusions}

In summary, several larvicidal essential oils, obtained from various Satureja species growing wild in Greece, were screened for the first time. These oils represent an inexpensive source of natural larvicidal substances for controlling mosquito larvae. However, further research is needed in order to evaluate the effectiveness of Satureja essential oils, explore their mode of action and establish their utility as natural larvicidal agents.

\section{Acknowledgements}

We would especially like to thank Dr. Aimilia Markelou for her assistance with the statistical analysis.

\section{Experimental}

\section{Plant Material}

Five plants of the Satureja genus, abundant in Greece, were collected for this study. The fresh plant material was collected in the summer of 2004 from various mountain sites in Greece. All plants were collected around their full flowering vegetative stage, which is richest in secondary metabolite content [33]. Full collection details are provided in Table 1. A voucher specimen of each plant is deposited in the herbarium of the Division of Pharmacognosy and Natural Products Chemistry, Department of Pharmacy, University of Athens, Athens, Greece.

\section{Isolation of the Essential Oils}

The freshly collected plant materials (steams, leaves and flowers) were washed thoroughly, finely chopped and subjected to steam distillation in a Clevenger-type apparatus for $3 \mathrm{~h}$ with $\mathrm{H}_{2} \mathrm{O}(3 \mathrm{~L})$ to produce the corresponding essential oils. The resulting oils were dried over anhydrous sodium sulphate and stored at $4{ }^{\circ} \mathrm{C}$. Their respective colours varied from light yellow for ST to light amber for SSP. Their yields are displayed in Table 2.

\section{Gas chromatography-Mass Spectrometry (GC/MS)}

GC analyses were carried out on a Perkin-Elmer, Clarus 500 gas chromatograph, fitted with a HP 5MS $30 \mathrm{~m} \times 0.25 \mathrm{~mm} \times 0.25 \mu \mathrm{m}$ film thickness capillary column and FID detector. The column temperature was programmed from $60{ }^{\circ} \mathrm{C}$ to $280{ }^{\circ} \mathrm{C}$ at a rate of $3{ }^{\circ} \mathrm{C} \mathrm{min}{ }^{-1}$. The injector and detector temperatures were programmed at $230{ }^{\circ} \mathrm{C}$ and $300{ }^{\circ} \mathrm{C}$ respectively. Helium was used as the carrier gas at a flow rate $1 \mathrm{mLmin}^{-1}$. The GC-MS analyses were performed using a Hewlett Packard 5973-6890 GC-MS system operating on EI mode (equipped with a HP 5MS 30 m x 0.25 mm x $0.25 \mu \mathrm{m}$ film thickness capillary column), using $\mathrm{He}\left(1 \mathrm{mLmin}^{-1}\right)$ as the carrier gas. The initial temperature of the column was $60{ }^{\circ} \mathrm{C}$ and then was gradually heated to $280{ }^{\circ} \mathrm{C}$ with a $3{ }^{\circ} \mathrm{C} \mathrm{min}{ }^{-1}$ rate. The identification 
of the compounds was based on comparison of their retention indices (RI) obtained using various nalkanes $\left(\mathrm{C}_{9}-\mathrm{C}_{24}\right)$, and by comparing their EI-mass spectra with the NIST/NBS, Wiley libraries spectra and literature [34, 35]. Additionally, the identity of each compound was confirmed by comparison with available authentic samples.

\section{Mosquito Rearing}

The larvicidal properties of the essential oil were evaluated under laboratory conditions against larvae of the mosquito species $C x$. pipiens biotype molestus. Mosquito larvae were collected from a colony which is being maintained in Benaki Phytopathological Institute, Kifissia, Greece for more than 20 years. Adults were kept in wooden framed cages $(33 \times 33 \times 33 \mathrm{~cm})$ with a $32 \times 32$ mesh at $25 \pm 2{ }^{\circ} \mathrm{C}$, $80 \pm 2 \%$ relative humidity and photoperiod of $14: 10$ (L:D) h. Cotton wicks saturated with $10 \%$ sucrose solution were used to as food source for the mosquitoes. Females laid eggs in round, plastic containers (10 $\mathrm{cm}$ diameter x $5 \mathrm{~cm}$ depth) filled with tap water $(150 \mathrm{~mL})$. Egg rafts were removed daily and placed in cylindrical enamel pans (with diameter of $35 \mathrm{~cm}$ and $10 \mathrm{~cm}$ deep), in order to hatch. Larvae were reared under the above mentioned conditions of temperature and light and were fed daily with baby fish food (TetraMin, Baby Fish Food) at a concentration of $0.25 \mathrm{gL}^{-1}$ of water until pupation. Pupae were then collected and introduced into the adult rearing cages.

\section{Larvicidal Bioassays}

Sufficient amounts of extract were transferred to a vial and the residual solvent was removed under high vacuum. Stock solutions were prepared in ethanol with a concentration of $1 \% \mathrm{wv}^{-1}$. A series of aqueous solutions with diverse concentration of essential oils, expressed as $\mathrm{mgL}^{-1}$, was made and tested under laboratory conditions.

The larval mortality bioassays were carried out according to a larval susceptibility test method suggested by the World Health Organization [36]. More specifically, twenty larvae were placed in a glass beaker along with aqueous suspension of essential oils $(250 \mathrm{~mL})$ at various concentrations (20 to $80 \mathrm{mgL}^{-1}$, depending on the extract tested). Each experiment was performed five times for each concentration and control treatment, with tap water included in each bioassay. Beakers with larvae were placed at $25 \pm 2{ }^{\circ} \mathrm{C}$ temperature, $80 \pm 2 \%$ relative humidity and a photoperiod of $14: 10$ (L:D) h. The percentage of dead larvae was determined and the data were further subjected to Probit analysis (SPSS 11.0).

\section{Principal Component Analysis (PCA)}

Principal component analysis (PCA) was performed using the MATLAB 7.1 software and used to delineate the interrelationship among plants collected and their larvicidal activities. 


\section{References}

1. Becker, N.; Petric, D.; Zgomba, M.; Boase, C.; Dahl, C.; Lane, J.; Kaiser, A. Mosquitoes and their control. Kluwer Academic/Plenum Publishers: New York, 2003.

2. Murgue, B.; Murri, S.; Zientara, S.; Durand, B.; Durand, J. P.; Zeller, H. West Nile outbreak in horses in Southern France, 2000: the return after 35 years. Emerg. Infect. Dis. 2001, 7, 692-696.

3. Lundström, J. O. Mosquito-borne viruses in Western Europe: a review. J. Vect. Ecol. 1999, 24, 139.

4. Campbell, G. L. ; Marfin, A. A.; Lanciotti, R. S.; Gubler, D. J. West Nile Virus. Lancet Infect. Dis. 2002, 2, 519-529.

5. Dauphin, G.; Zientara, S.; Zeller, H.; Murgue, B. West Nile: worlwide current situation in animals and humans. Comp. Immun. Microbiol. Infect. Dis. 2004, 27, 343-355.

6. Lindsay, S. W.; Birley, M. H. Climate change and malaria transmission. Ann. Trop. Med. Parasitol. 1996, 90, 573-588.

7. Olejnicek, J.; Gelbic, I.. Differences in response to temperature and density between two strains of the mosquito, Culex pipiens molestus Forskal. J. Vect. Ecol. 2000, 25, 136-145.

8. Hemingway, J.; Field, L.; Vontas, J. An Overview of Insecticide Resistance. Science 2002, 298, 96-97.

9. Hemingway, J.; Ranson, H. Insecticide Resistance in Insect Vectors of Human Disease. Ann. Rev. Entom. 2000, 45, 371-391.

10. Gubler, D. J. Aedes aegypi and Aedes aegypti-borne disease control in the 1990s: top down or bottom up. Am. J. Trop. Med. Hyg. 1989, 40, 571-578.

11. Chamberlain, K.; Pickett, J. A.; Woodcock, C. M. Plant signaling and induced defense in insect attack. Mol. Plant Physiol. 2000, 1, 67-72.

12. Sukumar, K.; Perich, M. J.; Boobar, L. R. Botanical derivatives in mosquito control: a review. $J$. Am. Mosq. Control Assoc. 1991, 7, 210-237.

13. Cheng, S.-S.; Liu, J.-Y.; Tsai, K.-H.; Chen, W.-J.; Chang, S.-T. Chemical Composition and Mosquito Larvicidal Activity of Essential Oils from Leaves of Different Cinnamomum osmophloeum Provanances. J. Agric. Food Chem. 2004, 52, 4395-4400.

14. El Hag, E. A.; El Nadi, A. H.; Zaitton, A. A. Toxic and Growth Retarding Effects of Three Plant Extracts on Culex pipiens Larvae (Diptera: Culicidae). Phytother. Res. 1999, 13, 388-392.

15. Jeyabalan, D.; Arul, N.; Thangamathi, P. Studies on effects of Pelargonium citrosa leaf extracts on malarial vector Anopheles stephensi Liston. Bioresource Technol. 2003, 89, 185-189.

16. Joseph, C. C.; Ndoile, M. M.; Malima, R. C.; Nkunya, M. H. H. Larvicidal and mosquitocidal extracts, a coumarin, isoflavonoids and pterocarpans from Neorautanemia mitis. Trans. Roy. Soc. Trop. Med. H. 2004, 98, 451-455.

17. Mongelli, E.; Coussio, J.; Ciccia, G. Investigation of the Larvicidal Activity of Pothomorphe peltata and Isolation of the Active Constituent. Phytother. Res. 2002, 16, S71-S72.

18. Rahuman, A. A.; Gopalakrishnan, G.; Ghouse, B. S.; Arumugam, S.; Himalayan, B. Effect of Feronia limonia on mosquito larvae. Fitoterapia 2000, 71, 553-555.

19. Ratnayake, R.; Karunaratne, V.; Ratnayake Bandara, B. M.; Kumar, V. Teo New Lactones with Mosquito Larvicidal Activity from Three Hortonia species. J. Nat. Prod. 2001, 64, 376-378. 
20. Trabousli, A. F.; El-Haj, S.; Tueni, M.; Taoubi, K.; Nader, N. A.; Mrad, A. Repellency and toxicity of aromatic plant extracts against the mosquito Culex pipiens molestus (Diptera: Culicidae). Pest Manag. Sci. 2005, 6, 597-604.

21. Trabousli, A. F.; Taoubi, K.; Samih, E.-H.; Bessiere, J. M.; Rammal, S. Insecticidal properties of essential plant oils against the mosquito Culex pipiens molestus (Diptera: Culicidae). Pest Manag. Sci. 2002, 58, 491-495.

22. Yang, Y.-C.; Lee, S.-G.; Lee, H.-K.; Kim, M.-K.; Lee, S.-H.; Lee, H.-S. A Piperidine Amide Extracted from Piper longum L. Fruit Shows Activity against Aedes aegypti Mosquito Larvae. $J$. Agric. Food Chem. 2002, 50, 3765-3767.

23. Yang, Y.-C.; Lim, M.-Y.; Lee, H.-S. Emodin Isolated from Cassia obtusifolia (Leguminosae) Seed Shows Larvicidal Activity against Three Mosquito Species. J. Agric. Food Chem. 2003, 51, 7629-7631.

24. Tutin, G. T.; Heywood, H. V.; Burges, A. N.; Moore, M. D.; Valentine, H. D.; Walters, M. S.; Webb, A. D. Flora Europaea. Cambridge University Press: London, 1972; Vol. 3.

25. Baydar, H.; Sagdic, O.; Ozkan, G.; Karadogan, T. Antibacterial activity and composition of essential oils from Origanum, Thymbra and Satureja species with commercial importance in Turkey. Food Con. 2004, 15, 169-172.

26. Chorianopoulos, N.; Kalpoutzakis, E.; Aligiannis, N.; Mitaku, S.; Nychas, G.-J.; Haroutounian, S. A. Essential oils of Satureja, Origanum, and Thymus species: chemical composition and antibacterial activities against foodborne pathogens. J. Agric. Food Chem. 2004, 52, 8261-8267.

27. Gulluce, M.; Sokmen, M.; Daferera, D.; Agar, G.; Ozkan, G.; Kartal, N.; Polissiou, M.; Sokmen, A.; Sahin, F. In vitro Antibacterial, Antifungal, and Antioxidant Activities of the Essential Oil and Methanol Extracts of Herbal Parts and Callus Cultures of Satureja hortensis L. J. Agric. Food Chem. 2003, 51, 3958-3965.

28. Chantraine, J.-M.; Laurent, D.; Ballivian, C.; Saavedra, G.; Ibanez, R.; Vilaseca, A. Insecticidal Activity of Essential Oils on Aedes aegypti Larvae. Pest Manag. Sci. 1998, 58, 491-495.

29. Regnault-Roger, C. The potential of botanical essential oils for insect pest control. Integ. Pest Manag. Sci. 1997, 2, 25-34.

30. Sivropoulou, A.; Papanikolaou, E.; Nikolaou, C.; Kokkini, S.; Lanaras, T.; Arsenakis, M. Antimicrobial and Cytotoxic Activities of Oreganum Essential Oils. J. Agric. Food Chem. 1996, 44, 1202-1205.

31. Vokou, S.; Kokkini, S.; Bessiere, J. M. Geographic variation of Greek oregano (Origanum vulgare ssp. hirtum) essential oils. Biochem. Syst. Ecol. 1993, 21, 287-295.

32. Trabousli, A. F.; Taoubi, K.; Samih, E.-H.; Bessiere, J. M.; Rammal, S. Incecticidal properties of essential oils against the mosquito Culex pipiens molestus (Diptera: Culicidae). Pestic. Manag. Sci. 2002, 58, 491-495.

33. Chorianopoulos, N.G.; Evergetis, E.; Mallouchos, A.; Kalpoutzakis, E.; Nychas, G.-J.; Haroutounian, S. A. Characterization of the Essential Oil Volatiles of Satureja thymbra and Satureja parnassica: Influence of Harvesting Time and Antimicrobial Activity. J. Agric. Food Chem. 2006, 54, 3139-3145.

34. Adams, R. Identification of essential oil components by Gas Chromatography/Mass Spectroscopy. Allured Publishing: Carol Stream, IL, 1995. 
35. Massada, Y. Analysis of essential oil by Gas Chromatography and Spectrometry. Wiley: New York, 1976.

36. WHO. Instructions for determining the susceptibility or resistance of mosquito larvae to insecticides. WHO/VBC/81.807, World Health Organization: Geneva, 1981.

Sample availability: Available from the authors.

(C) 2007 by MDPI (http://www.mdpi.org). Reproduction is permitted for noncommercial purposes. 